\title{
A reação da elite política incumbente na abertura democrática brasileira
}

\section{RAPHAEL BRUCE RUDI ROCHA*}

\begin{abstract}
RESUMO: Este artigo analisa um dos possíveis canais através dos quais as elites incumbentes alinhadas com a ditadura brasileira foram capazes de reter o seu poder político durante a democratização na década de 1980. Com base em dados do PNAD e resultados de eleições legislativas, verificamos primeiro que os eleitores analfabetos que viviam nos estados que foram dominados pelo partido de elite durante a ditadura tinham uma probabilidade maior de se registar para votar do que aqueles que viviam em outros estados. Investigamos então se esta correlação positiva representa uma reação das elites incumbentes a fim de manter o seu poder político através da manipulação do eleitor ou se representa uma reação destes eleitores, a fim de tirar o poder das oligarquias. Constatamos que, em estados dominados pelo partido de elite, os analfabetos apresentaram maior probabilidade de estarem politicamente desinteressados e desinformados. Nossos resultados sugerem que uma reação politicamente motivada a partir desta população é implausível.

PALAVRAS-CHAVE: democratização; elites; oligarquia rural.
\end{abstract}

ABSTRACT: The reaction of the political incumbent elites in the Brazilian democratic opening. This paper examines one of the possible channels through which incumbent elites aligned with the Brazilian dictatorship were able to withhold their political power during the democratization in the 1980s. Based on national household survey data and results from legislative elections, we first find that recently franchised illiterate voters who lived in states that were dominated by the elite party during the dictatorship had a higher probability to register to vote than those who lived in other states. We then investigate whether this positive correlation represents a reaction from the incumbent elites in order to keep their political power through voter manipulation or a reaction from these voters in order to

\footnotetext{
* Raphael Bruce é aluno do Mestrado em Economia do Instituto de Pesquisas Econômicas da Universidade de São Paulo (IPE-USP). E-mail: raphaelbruce@usp.br; Rudi Rocha é Professor Adjunto do Instituto de Economia da Universidade Federal do Rio de Janeiro (IE/UFRJ). Email: rudi.rocha@ ie.ufrj.br. Os autores são gratos pelos comentários e sugestões de Eduardo Bastian, Fernando Carnaúba, Gabriel Corrêa, Fernanda Estevan, Pedro Funari, Frances Hagopian, Marcos Nakaguma, Bruno Ottoni e Graziella Testa. Todos os erros ou omissões são de total responsabilidade dos autores. Submetido; 22/ feverereiro/2014; Aprovado: 19/agosto/2014.
} 
remove the power from the oligarchies. We find that, in states dominated by the elite party, illiterates had higher probability of being politically uninterested and uninformed. Our results suggest that a politically motivated reaction from this population is implausible KEYWORDS: democratization; elites; rural oligarchy.

JEL Classification: D72; D78; I25.

\section{INTRODUÇÃO}

A democracia e o sufrágio universal tornaram-se realidade ao longo da segunda metade do século passado em um grande número de países em desenvolvimento. No entanto, em muitos casos essa recente equidade na distribuição de direitos políticos de jure tem convivido com a desigualdade de poder político de facto e a persistência da pobreza e desigualdade econômica. Neste sentido, a hipótese de que a democratização teria um efeito causal positivo sobre equidade e desenvolvimento parece dificilmente válida.

Este artigo tem como objetivo investigar, com base no caso brasileiro, duas possíveis explicações para a persistência na desigualdade de poder político de facto no período pós-democratização. Primeiro, a distribuição do poder político após transição de regime é, em alguma medida, variável de escolha da elite autoritária incumbente. Ante a perda do poder político de jure, essa elite busca formas de reagir e realocar recursos de modo a se manter no poder sob o novo regime democrático e anular mudanças institucionais (Acemoglu e Robinson, 2006, 2008; Aghion et al.,, 2004). A literatura costuma reconhecer como formas de reação as práticas de compra de votos, fraude eleitoral, lobbying, coerção, ou mesmo o uso de forças paramilitares.

Uma explicação alternativa para o fracasso ou sucesso da transição democrática, e de seus efeitos sobre o desenvolvimento, pode estar também no comportamento dos novos atores do cenário político, os eleitores. Muito pouco se sabe acerca dos possíveis impactos da ditadura e de longos períodos de autoritarismo sobre a formação cívica e a participação política dos cidadãos ${ }^{1}$. Por um lado, pode-se argumentar que a inexistência da cultura democrática por longos períodos e a falta de experiência dos cidadãos enquanto eleitores podem levar à desintegração de formas de ação coletiva, à falta de interesse político, ou mesmo à resignação. Neste caso, a antiga elite poderá incorrer em um custo relativamente baixo para se manter ou voltar ao poder via eleições no período pós-transição democrática. Por outro lado, é possível argumentar também que longos períodos de autoritarismo podem levar a uma participação política dos cidadãos relativamente maior no período democrático, em particular daqueles que mais sofreram os efeitos deste autoritarismo e que agora têm a oportunidade de se manifestar através do voto e fazer valer suas preferências (Baland e Robinson, 2008; Bellows e Miguel, 2009; Blattman, 2009). Por exemplo,

\footnotetext{
${ }^{1}$ Assim como Verba et al., (2000), entendemos participação política como qualquer ato que busca influenciar as decisões de governantes ou as políticas que eles formulam e implementam.
} 
Baland e Robinson (2008) mostram que a introdução do voto secreto no Chile mudou o comportamento dos eleitores em localidades dominadas por grandes proprietários de terra. O partido associado aos proprietários perdeu votos nas eleições pós-mudança. Artigos examinando a relação entre conflito civil e ação coletiva em países da África mostram que os indivíduos que mais sofreram com a violência e a intensidade da violência são aqueles que tendem a participar mais da vida política da comunidade local no pós-conflito (Bellows e Miguel, 2009; Blattman, 2009).

É possível dizer, portanto, que as consequências de um processo de democratização são em parte determinadas tanto pela capacidade de reação da antiga elite às novas regras, quanto ao nível de engajamento político dos cidadãos. Apesar da evidente importância da compreensão desse processo e de seus determinantes, a relação tripla entre democratização, comportamento das elites, e participação política, ainda é pouco compreendida dentro da literatura empírica em economia e política comparada.

Este artigo investiga hipóteses sobre o comportamento da elite incumbente e de eleitores durante a democratização brasileira nos anos 1980. Em 1985 o direito ao voto foi estendido aos analfabetos no Brasil. Em primeiro lugar testamos em que medida a participação política deste grupo de novos eleitores variou conforme o poder político de jure que o partido político de base do governo autoritário exercia em nível local durante a ditadura. Mais especificamente, utilizamos os microdados sobre participação política do suplemento da Pesquisa Nacional por Amostra de Domicílios (PNAD) de 1988 para testar qual a relação entre uma forte presença da Aliança Renovadora Nacional (ARENA) em nível estadual durante a ditadura e a participação política de analfabetos no final dos anos 1980. Desse modo, investigamos (i) como um grupo de eleitores excluídos do processo político se comporta ao receber o poder de manifestar suas preferências após um longo período de autoritarismo; e (ii) se este comportamento varia conforme o poder político exercido pela elite política incumbente durante a ditadura.

Como resultado deste primeiro teste, documentamos uma forte correlação positiva entre a força da ARENA nos estados e o número de analfabetos que tiraram o título eleitoral entre 1985 e 1988. Esse resultado é particularmente robusto entre trabalhadores agrícolas e entre os mais pobres. Investigamos então se a relação positiva entre poder político das elites durante a ditadura e participação política dos analfabetos após a democratização representou (i) uma reação da elite nesses estados perante a perda de poder político de jure durante a transição democrática, ou (ii) uma reação por parte destes novos eleitores em direção a uma participação política maior em locais onde a elite incumbente detinha, e possivelmente exercia, mais poder político. Para isso, utilizamos itens do suplemento da PNAD sobre quão informados e interessados politicamente eram os respondentes. Os resultados sugerem não existir qualquer relação entre poder político da ARENA e interesse ou grau de informação sobre política entre analfabetos após a transição. Verificamos, portanto, que os analfabetos tiraram relativamente mais títulos eleitorais em locais antes dominados pela ARENA, embora não revelem nenhum particular interesse por temas políticos de acordo com outras variáveis contidas no 
suplemento da PNAD. Esse último resultado enfraquece a hipótese de reação por parte dos eleitores. Mais do que isso, o conjunto de resultados deste artigo não nos permite rejeitar a hipótese de que a elite incumbente reagiu à perda de poder político de jure realocando recursos de modo a conquistar o novo eleitorado e se manter no poder sob o novo regime democrático. O fato de observarmos uma heterogeneidade particular com relação a trabalhadores agrícolas sugere que a elite incumbente pode ter se valido de relações patriarcais ou coercitivas no meio rural, onde a assimetria de poder de barganha entre oligarcas e trabalhadores é maior e, portanto, o custo de reação da elite é relativamente menor.

Este artigo está dividido em cinco seções, além desta introdução. A segunda seção descreve brevemente o contexto histórico e institucional do período aqui estudado. $\mathrm{Na}$ terceira seção descrevemos os dados e estatísticas descritivas. $\mathrm{Na}$ seção seguinte apresentamos o modelo empírico e os resultados. Por último, na quinta seção, apresentamos os comentários finais.

\section{CONTEXTO INSTITUCIONAL}

Em 1964, o então presidente João Goulart teve seu governo derrubado pelo golpe liderado pelos militares. A queda do presidente representou uma reação dos segmentos da sociedade insatisfeitos com a plataforma de Goulart, que priorizava políticas redistributivas que poderiam ameaçar o status quo econômico. Uma vez no poder, o novo regime procurou reorganizar o sistema político através da centralização do poder em torno do executivo. Tal medida buscava reorganizar um sistema político marcado pela corrupção e por práticas clientelistas, problemas vistos pelos militares como entraves para o crescimento econômico. O novo arranjo institucional teve como consequência uma redução na autonomia fiscal dos estados e dos municípios, alterando a distribuição de poder entre os membros da elite política (Houtzager e Kurtz, 2000). Em 1965, com a derrota de vários candidatos apoiados pelos militares em eleições estaduais, o regime aboliu as eleições diretas, os partidos políticos então existentes, e instituiu um sistema bipartidário composto somente pela Aliança Renovadora Nacional (ARENA) e pelo Movimento Democrático Brasileiro (MDB).

A mudança em direção a um regime centralizado no Executivo federal, no entanto, não teve reflexo sobre a distribuição do poder político de facto. O que se viu foi uma acomodação da antiga elite e um aprofundamento das relações de poder que existiam antes do golpe. Segundo Hagopian,

Authoritarianism enhanced the effectiveness of state clientelism for both the regime and the oligarchy. Authoritarianism was the regime's sti$\mathrm{ck}$, and clientelism was the carrot for dissuading opposition and to build support. Authoritarianism allowed the oligarchy to exist, who organized clientelistic networks within the ARENA party to secure its grip on the state, and retain its monopoly of the distribution of state resources. In- 
cumbents, naturally advantaged in a clientelistic system, became virtually invincible in a system in which competition was sharply reduced by law and practice. (Hagopian, 1975, p. 278)

O regime permitiu, portanto, a persistência das elites e das instituições locais que lhes davam suporte desde antes de 1964. Em especial, após a perda de poder da ARENA nas eleições de 1974, o regime militar se tornou ainda mais dependente do apoio político gerado por práticas clientelistas (Cammack, 1982). Limongi (2012) caracteriza a "completa inversão do sistema representativo" como consequência dessa falta de autonomia do município, onde uma facção oligárquica local, uma vez de posse do poder de jure, se vale do uso da violência, legal ou extralegal, como ferramenta para a manutenção do poder de facto. O sistema é então invertido, pois a maioria não escolhe livremente seus governantes, mas é induzida pelo alinhamento prévio entre a elite local e as forças dominantes no plano estadual e federal. Em outras palavras, a vantagem de incumbência da oligarquia é tão grande quanto menor a autonomia legal e financeira do município. Como o que se viu durante o período autoritário foi justamente a centralização em torno do Executivo federal em detrimento dos municípios, é razoável observar um fortalecimento do poder de facto da elite local que se alinhou à ditadura.

A oposição política ao regime era representada pelo $\mathrm{MDB}$, que tinha como principais bases de apoio político os grandes centros urbanos. Aqueles alinhados com o governo militar (membros da ARENA) buscaram se fortalecer em seus estados, onde seus poderes locais se aprofundaram e as antigas práticas políticas se perpetuaram (Hagopian, 1996). Em particular, o apoio à ARENA durante o regime tinha uma relação inversa com o grau de urbanização dos municípios (Kinzo, 1988). Segundo Power (2000), a dependência de transferências do governo era particularmente grande em áreas rurais, lugares onde a população tinha pouco ou nenhum conhecimento a respeito do debate político existente na época, e das políticas públicas formuladas pelo governo militar devido à pouca quantidade de informação que chegava a essa parcela da população. Esses fatores contribuíam para a criação de um ambiente favorável à criação e estreitamento de relações clientelistas. Como caracterizado por Leal

Completamente analfabeto, ou quase, sem assistência médica, não lendo jornais, nem revistas, nas quais se limita a ver as figuras, o trabalhador rural, a não ser em casos esporádicos, tem o patrão na conta de benfeitor. E é dele, na verdade, que recebe os únicos favores que sua obscura existência conhece. Em sua situação, seria ilusório pretender que esse novo pária tivesse consciência do seu direito a uma vida melhor e lutasse por ele com independência cívica. O lógico é o que presenciamos: no plano político, ele luta com o "coronel" e pelo "coronel”. (Leal, 1949, p. 25)

Podemos identificar, portanto, a ARENA como a coalizão que representava a oligarquia rural e por ela era apoiada. Tal relação possibilitou a esta oligarquia manter tanto o poder político de jure como o de facto ao longo da redistribuição 
do poder político de jure ocorrida durante a ditadura. Neste artigo investigamos hipóteses sobre como esta mesma elite incumbente buscou manter o poder político diante das mudanças na redistribuição do poder de jure durante a transição democrática. Investigamos também o comportamento político durante esta transição dos analfabetos quando lhes foi dado o direito ao voto, ou seja, quando o poder político de jure foi redistribuído.

\section{DADOS}

Nossa análise se baseia em dados da Pesquisa Nacional de Amostra de Domicílios (PNAD) de 1988. Um elemento especial dessa edição da PNAD é o suplemento que contém um questionário sobre o conhecimento e percepção política dos respondentes. A amostra utilizada em nossa análise econométrica se restringe somente aos analfabetos maiores de 18 anos não residentes no DF ou região Norte. A principal variável dependente que utilizamos é uma dummy que indica se o indivíduo tinha título de eleitor no momento da entrevista. Utilizamos dados a respeito das eleições legislativas em 1966 como uma proxy para a presença da ARENA em cada unidade da federação durante o regime militar. Mais precisamente, essa proxy refere-se ao percentual de votos obtidos pela ARENA, em cada estado, na eleições de 1966 para o Legislativo federal. Usamos como uma proxy alternativa a fração de cadeiras tomadas por esse partido nas eleições de 1974. Ambas as proxies podem ser encontradas desagregadas por estado na Tabela 1. (As tabelas e a figura estão agrupados no final do artigo.)

A amostra final que utilizamos em nossa análise empírica contém 31.201 indivíduos analfabetos. A Tabela 2 apresenta as estatísticas descritivas para os analfabetos em comparação aos não analfabetos. Entre a população alfabetizada, $94 \%$ dos indivíduos tinham título de eleitor. O nível de conhecimento político também era relativamente alto para essa população, com cerca de $90 \%$ dos respondentes afirmando que conheciam o nome dos candidatos eleitos. Quando questionados a respeito do critério utilizado para decidir em qual candidato votar, $72,35 \%$ dos alfabetizados declararam se basear apenas no candidato, $12,41 \%$ apenas no partido e somente $5,46 \%$ não tinham um critério claro. A maior parte dessa população vivia em áreas urbanas e com acesso direto aos meios de informação. Entre os analfabetos, apenas $56,42 \%$ se baseavam em características do candidato para escolher em quem votar, enquanto $18,55 \%$ não tinham critério algum para decidir o voto. A maior parte dos analfabetos vivia em áreas rurais e trabalhava no ramo agrícola. Apenas uma pequena proporção deles assistia TV, sendo o rádio o principal veículo pelo qual eles tinham acesso à informação.

Observamos que $74 \%$ dos analfabetos tinham título eleitoral no momento da entrevista, ou seja, três anos após ser concedido aos analfabetos o direito ao voto. A Figura 1, no entanto, mostra grande heterogeneidade entre unidades da federação no percentual de analfabetos com título de eleitor. Em estados onde a ARENA era o partido dominante, como Ceará e Piauí, a proporção de analfabetos registrados passa de $80 \%$, enquanto em estados onde esse partido era mais fraco, como São 
Paulo e Rio de Janeiro, essa proporção era de aproximadamente $60 \%$. À primeira vista, esse resultado não é consistente com a visão de que a participação política é positivamente correlacionada com o desenvolvimento. O resultado é, porém, consistente com as duas possíveis explicações para esse comportamento contraintuitivo por parte dos cidadãos analfabetos. Por um lado, esse resultado é consistente com a hipótese de que houve uma reação incitada pela elite política em estados dominados pela ARENA, que buscou a manutenção do seu poder de jure durante a transição eventualmente por meio de métodos coercitivos ou manipulação eleitoral. Por outro lado, o resultado é também consistente com a hipótese alternativa de que a população analfabeta, após receber o direito ao voto, manifesta nas urnas sua insatisfação com o regime autoritário e a oligarquia política a ela associada, em uma tentativa de remover a elite incumbente do poder. Na próxima seção confrontamos empiricamente essas duas hipóteses.

\section{OS ELEITORES E A REAÇÃO DA ELITE}

Para investigar a relação entre o poder político da ARENA e o comportamento dos eleitores analfabetos durante a transição democrática, primeiro rodamos a seguinte regressão em nível individual:

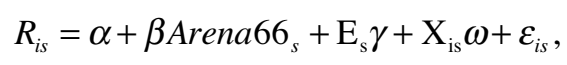

onde $R_{i s}$ é uma dummy que indica se o indivíduo $i$ na UF $s$ possui título eleitoral no ano de 1988. O termo Arena66 se a porcentagem de votos obtidos pela ARENA nas eleições legislativas de 1966, e é nossa proxy para a força da elite política no estado $s$. O termo $\mathrm{E}_{\mathrm{s}}$ é uma matriz de controles em nível estadual, tais como latitude, log do PIB per capita, e porcentagem de indivíduos alfabetizados no estado $s$; enquanto $\mathbf{X}_{\text {is }}$ é uma matriz de controles em nível individual. Em todas as regressões estimamos erros-padrão robustos a autocorrelação serial no nível das UFs. Nosso coeficiente de interesse nessa primeira regressão é $\beta$, que captura a correlação entre o poder que a ARENA detinha na UF durante a ditadura e a participação política dos analfabetos após a democratização.

A Tabela 3 apresenta os resultados. Em todas as colunas observamos uma associação positiva e robusta entre a presença da ARENA e participação política de analfabetos. Isso confirma a correlação vista na Figura 1. Encontramos um coeficiente estável para a variável de interesse Arena sentre as colunas (2) e (4), quando passamos a introduzir controles em nível individual. Na última coluna nos concentramos sobre a amostra de ocupados, e assim podemos verificar a relação entre participação política e ocupação em atividades agrícolas. Nesta especificação, um aumento de 10 pontos percentuais no percentual de votos da ARENA em 1966 (aproximadamente 1 desvio-padrão da distribuição desta variável entre estados) está associado a um incremento de 2,4 pontos percentuais na probabilidade de um analfabeto ter título eleitoral em 1988. Além disso, é importante notar dois outros conjuntos de coeficientes encontrados. Primeiro, nenhum outro controle no nível dos estados é significativamente associado à participação política. Segundo, na 
última especificação observamos que a variável dependente é negativamente correlacionada com a renda per capita dos analfabetos e positivamente correlacionada com o nível de acesso à informação (ter rádio e assistir TV semanalmente). Encontramos também uma associação negativa e robusta com o fato desses indivíduos trabalharem no ramo agrícola.

Buscamos investigar então heterogeneidades na relação entre ARENA, participação política e características socioeconômicas. Na Tabela 4 apresentamos regressões, onde interagimos a variável referente à presença da ARENA com um conjunto de outras variáveis explicativas, sendo todas as especificações condicionais em efeitos fixos para estados. Dois resultados relevantes se destacam. Em primeiro lugar, a interação entre ARENA e o fato do trabalhador ser do ramo agrícola tem uma correlação positiva e robusta com o nível de participação política do indivíduo, enquanto o coeficiente para a interação entre a presença da ARENA e o fato do trabalhador morar em uma área rural não é significativa. Em segundo lugar observamos que a interação entre ARENA e renda domiciliar per capita é negativa. Ou seja, em estados onde a ARENA era mais forte a probabilidade dos analfabetos mais pobres terem título de eleitor era relativamente maior. Com relação à interação entre ARENA e acesso à informação, encontramos coeficientes negativos, porém não significativos. Apesar de não significativos, eles sugerem que são os indivíduos com menos acesso à informação que tinham probabilidade maior de tirar título eleitoral em estados onde a ARENA era mais forte.

Como este último resultado é apenas sugestivo, ainda não podemos descartar nenhuma de nossas duas hipóteses alternativas a respeito do comportamento dos eleitores e dos membros da elite política:

I. Os membros da elite incumbente reagiram ante a perda iminente de seu poder de jure e buscaram persuadir a parcela da população com baixo nível de escolaridade e vulnerável, eventualmente por meio de coerção direta ou compra de votos. Essa reação pode ter sido facilitada pelo isolamento geográfico dos trabalhadores agrícolas, que já viviam sob relações coercivas de trabalho.

II. Uma parcela de trabalhadores oprimidos, que pela primeira vez tem a chance de manifestar sua insatisfação com a elite incumbente, aproveita a oportunidade para tentar remover do poder as oligarquias locais.

Para identificarmos qual dessas alternativas nos dá a explicação mais plausível para os nossos resultados, comparamos então o nível de conhecimento político e participação cívica entre os analfabetos que viviam em estados com presença mais ou menos forte da ARENA. Começamos nossa análise a partir das respostas dadas pelos indivíduos para as três perguntas relacionadas ao nível de informação que eles tinham a respeito dos políticos em cargos do Executivo no momento da pesquisa. Também investigamos atitudes relacionadas à participação política por meio de perguntas em que o respondente diz se fazia ou não parte de um sindicato ou se era filiado a algum partido. Por fim usamos como variável dependente uma dummy que indica se o respondente tinha algum critério para votar (ou, alternativamente, se no momento do voto seguia o partido ou o candidato).

A Tabela 5 apresenta os resultados. Em primeiro lugar observamos que a inte- 
ração entre ARENA e ocupação agrícola não é significativa em nenhuma das colunas, com exceção da última. Ou seja, apesar de observarmos a probabilidade mais alta desses indivíduos em ter título eleitoral em locais onde a presença da ARENA era mais forte, eles não aparentam conhecer relativamente melhor o nome dos políticos incumbentes no Executivo. Também não demonstram uma probabilidade maior de serem filiados a partidos ou sindicatos. Por fim, na última coluna, observamos que estes indivíduos apresentam uma probabilidade relativamente maior de não seguirem qualquer critério em particular no momento do voto.

Em segundo lugar, observamos que os indivíduos com menos acesso à informação demonstram conhecer melhor o nome dos políticos incumbentes onde a presença da ARENA é mais forte, embora esses mesmos indivíduos não aparentem participar da vida política de forma mais ativa por meio de partidos e sindicatos. Encontramos também que, em locais onde a ARENA é mais forte, são os indivíduos com mais acesso à informação (ouvem rádio) que declararam não ter critério claro na hora do voto. Um padrão similar é encontrado quando observamos a interação entre ARENA e renda domiciliar per capita. São os mais pobres que conhecem relativamente melhor o nome de políticos incumbentes, embora não exista nenhum padrão que indique uma participação política dos mais pobres mais ativa nas demais dimensões.

As evidências empíricas encontradas na literatura indicam que o status socioeconômico dos indivíduos é positivamente correlacionado com o seu nível de participação política (Verba e Nie, 1972). Autores como Wolfinger e Rosenstone (1980), Milligan, Moretti e Oreopoulos (2004), Dee (2004), Glaeser, Ponzetto e Shleifer (2007) fornecem evidência empírica nessa direção. Larcinese (2007) mostra que a probabilidade de um indivíduo participar das eleições aumenta com o nível de informação política dele. Essas evidências nos ajudam a identificar a natureza por trás da decisão dos analfabetos que viviam em estados com presença mais forte da ARENA em se registrarem para participar das eleições após a transição democrática. Observamos que uma parcela da população politicamente desinteressada e desinformada procurou manifestar suas preferências nas urnas, justamente em estados onde a elite incumbente enfrentava a perda iminente de seu poder de jure. Logo, nossos resultados sugerem que a hipótese de uma reação política dos eleitores é pouco plausível em nosso contexto, já que eles não demonstram um nível particularmente alto de interesse político e participação cívica. Neste caso, os resultados apresentados, embora sugestivos, são consistentes com a hipótese de que os membros da elite incumbente reagiram perante a uma perda iminente de seu poder de jure e eventualmente buscaram persuadir a parcela da população com baixo nível de escolaridade e vulnerável, por meio de relações clientelistas, coerção direta, compra de votos ou outros mecanismos de reação. Essa resposta pode ter sido facilitada pelo isolamento geográfico dos trabalhadores agrícolas, que em geral viviam sob relações coercivas de trabalho.

\section{CONCLUSÃO}

Este artigo investigou um possível canal por meio do qual a elite incumbente 
buscou manter seu poder político durante a transição democrática dos anos 1980 . Para isso, observamos a participação política dos analfabetos na segunda metade dessa década em estados dominados pelo partido então alinhado com as elites oligárquicas e com a ditadura. Encontramos uma correlação positiva significante entre a presença da ARENA e a proporção de analfabetos que se registraram como eleitores entre 1985 e 1988.

Comparamos então duas explicações possíveis para esse padrão: (i) o registro de analfabetos nessas áreas representou uma reação da elite incumbente, que tentava manter seu poder político a partir do voto dos analfabetos; (ii) esse grupo historicamente oprimido e que nunca teve a chance de reagir contra a elite por meio do voto agora pode manifestar suas insatisfação e remover do poder as oligarquias políticas. Os resultados sugerem que a hipótese de uma reação política dos eleitores é pouco plausível, já que eles não demonstram interesse político ou participação cívica particularmente mais alta em locais onde a presença da ARENA era mais forte. Neste caso, os resultados apresentados são consistentes com a hipótese de que a elite incumbente reagiu ante a uma perda de poder político de jure ao buscar o voto dos analfabetos, a parcela da população com baixo nível de escolaridade e mais vulnerável ao clientelismo, coerção direta, compra de votos ou outros mecanismos de reação.

Figura 1: Correlação entre a proporção de analfabetos com título e presença da ARENA

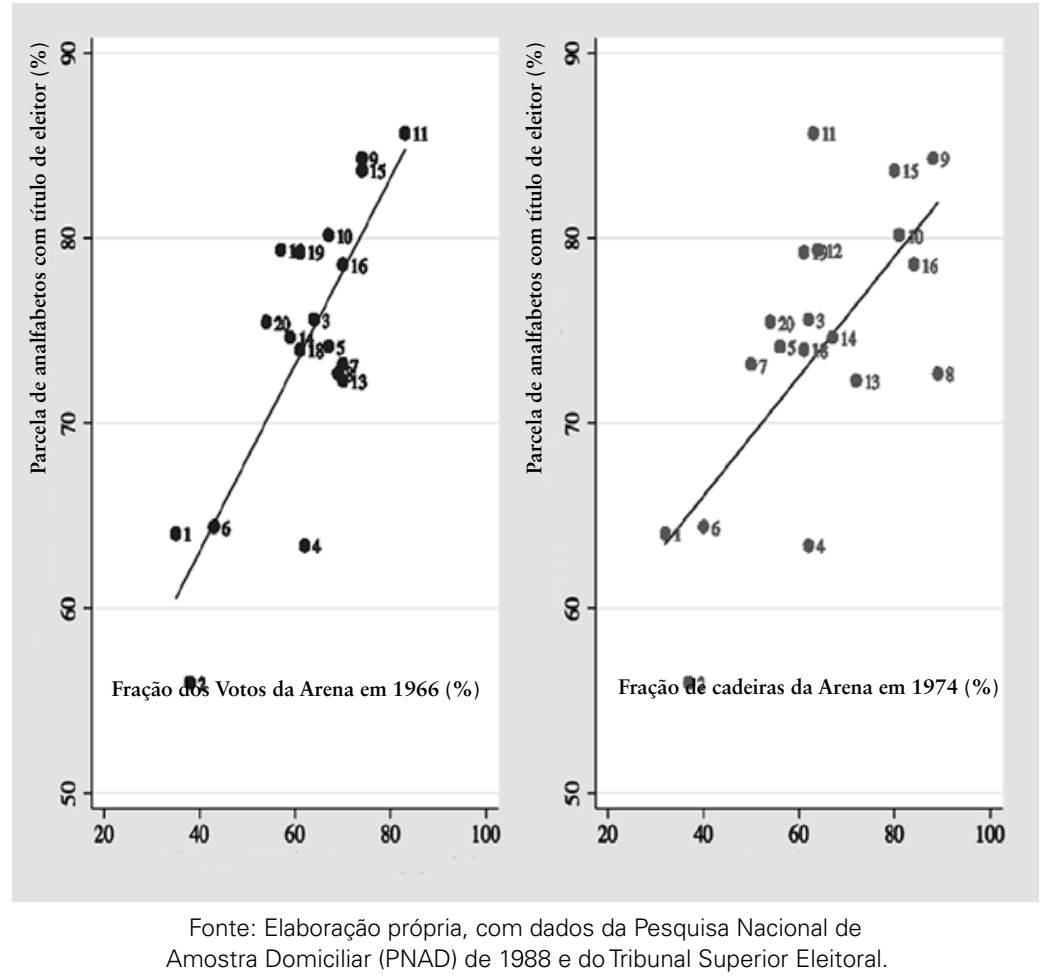


Tabela 1: Resultado eleitoral por UF (exceto a região Norte)

\begin{tabular}{|c|c|c|c|}
\hline Código & UF & $\begin{array}{c}\text { Fração dos votos } \\
\text { em } 1966(\%)\end{array}$ & $\begin{array}{l}\text { Fração de assentos } \\
\quad \text { em } 1974(\%)\end{array}$ \\
\hline 1 & RJ & 35 & 32 \\
\hline 2 & SP & 38 & 37 \\
\hline 3 & MG & 64 & 62 \\
\hline 4 & ES & 62 & 62 \\
\hline 5 & SC & 67 & 56 \\
\hline 6 & RS & 43 & 40 \\
\hline 7 & PR & 70 & 50 \\
\hline 8 & MA & 69 & 89 \\
\hline 9 & $\mathrm{Pl}$ & 74 & 88 \\
\hline 10 & CE & 67 & 81 \\
\hline 11 & RN & 83 & 63 \\
\hline 12 & PB & 57 & 64 \\
\hline 13 & PE & 70 & 72 \\
\hline 14 & $\mathrm{AL}$ & 59 & 67 \\
\hline 15 & SE & 74 & 80 \\
\hline 16 & BA & 70 & 84 \\
\hline 17 & DF & - & - \\
\hline 18 & MS & 61 & 61 \\
\hline 19 & MT & 61 & 61 \\
\hline 20 & $\mathrm{GO}$ & 54 & 54 \\
\hline
\end{tabular}

Fonte: Elaboração própria, com dados do Tribunal Superior Eleitoral. 


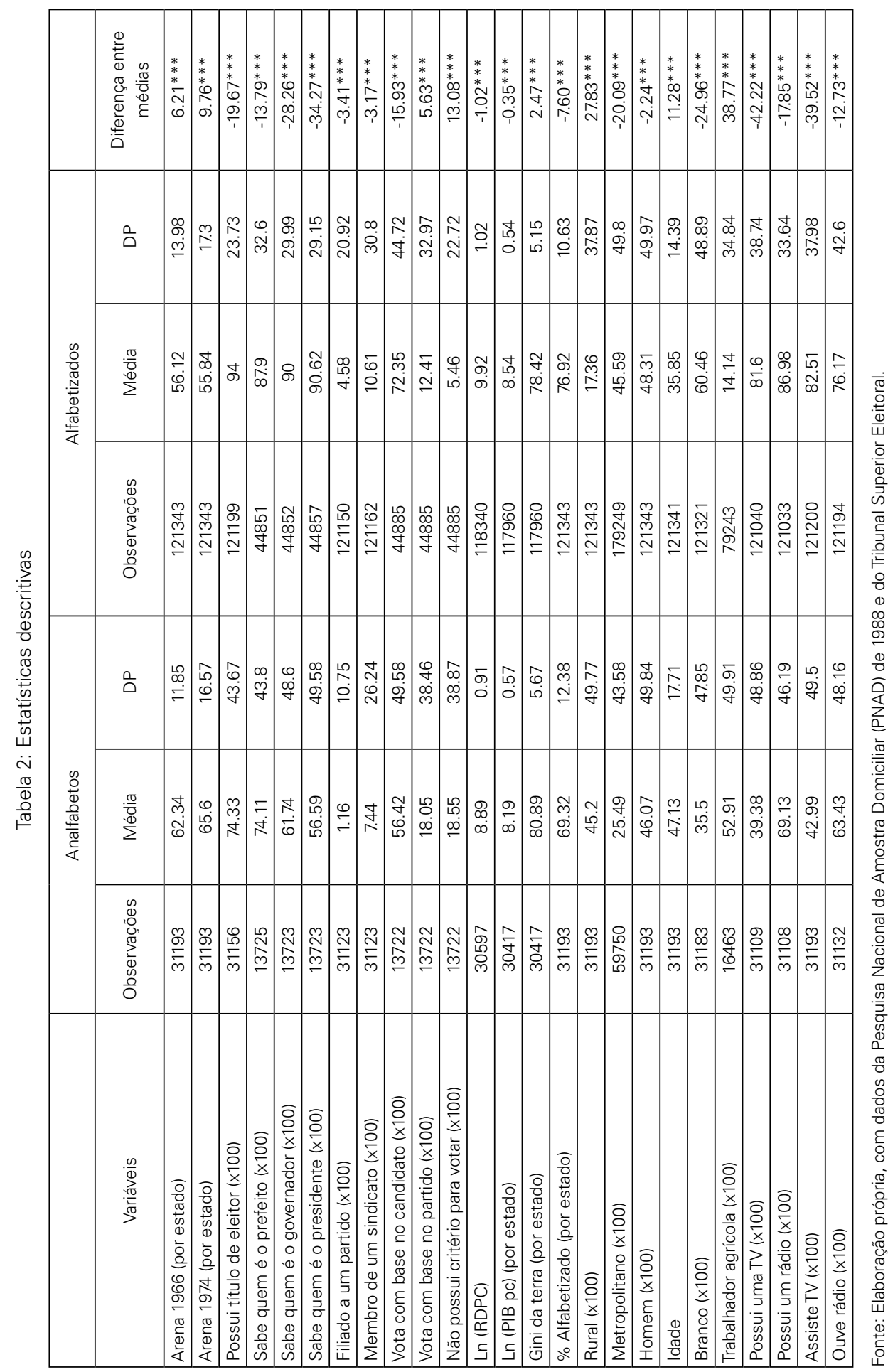


Tabela 3: Relação entre o poder da ARENA durante a ditadura e o registro eleitoral de analfabetos após a democratização

\begin{tabular}{|c|c|c|c|c|}
\hline & \multicolumn{4}{|c|}{ Variável dependente: Tem título eleitoral (dummy) } \\
\hline & (1) & (2) & (3) & (4) \\
\hline \multirow[t]{2}{*}{ Arena } & 0.429 & 0.336 & 0.339 & 0.238 \\
\hline & $(0.085)^{* * *}$ & $(0.095)^{* * *}$ & $(0.095)^{* * *}$ & $(0.058)^{* * *}$ \\
\hline \multirow[t]{2}{*}{ Latitude } & 0.000 & -0.001 & -0.000 & -0.001 \\
\hline & $(0.003)$ & $(0.003)$ & $(0.003)$ & $(0.002)$ \\
\hline \multirow[t]{2}{*}{$\operatorname{Ln}(\mathrm{PIB} p c)$} & -0.096 & -0.067 & -0.065 & -0.023 \\
\hline & $(0.046)^{*}$ & (0.046) & (0.045) & $(0.033)$ \\
\hline \multirow[t]{2}{*}{ Gini Terra } & 0.001 & 0.002 & 0.002 & -0.000 \\
\hline & $(0.003)$ & $(0.003)$ & $(0.003)$ & $(0.003)$ \\
\hline \multirow[t]{2}{*}{$\%$ Alfabetizados na UF } & 0.003 & 0.003 & 0.003 & 0.001 \\
\hline & $(0.002)$ & $(0.002)$ & $(0.002)$ & $(0.002)$ \\
\hline \multirow[t]{2}{*}{ Rural } & & 0.002 & 0.005 & 0.014 \\
\hline & & $(0.007)$ & $(0.007)$ & (0.009) \\
\hline \multirow[t]{2}{*}{ Metropolitano } & & -0.045 & -0.048 & -0.052 \\
\hline & & $(0.034)$ & (0.034) & $(0.020)^{* *}$ \\
\hline \multirow[t]{2}{*}{ Homem } & & 0.133 & 0.132 & 0.095 \\
\hline & & $(0.016)^{* * *}$ & $(0.017)^{* * *}$ & $(0.011)^{* * *}$ \\
\hline \multirow[t]{2}{*}{ Idade } & & 0.024 & 0.024 & 0.020 \\
\hline & & $(0.001)^{* * *}$ & $(0.001)^{* * *}$ & $(0.001)^{* * *}$ \\
\hline \multirow[t]{2}{*}{ Idade2 } & & -0.000 & -0.000 & -0.000 \\
\hline & & $(0.000)^{* * *}$ & $(0.000)^{* * *}$ & $(0.000)^{* * *}$ \\
\hline \multirow[t]{2}{*}{ Branco } & & -0.025 & -0.026 & 0.006 \\
\hline & & $(0.010)^{* *}$ & $(0.010)^{* *}$ & $(0.006)$ \\
\hline \multirow[t]{2}{*}{$\operatorname{Ln}(\mathrm{RDPC})$} & & -0.010 & -0.011 & -0.012 \\
\hline & & $(0.004)^{* *}$ & $(0.004)^{* * *}$ & $(0.005)^{* *}$ \\
\hline \multirow[t]{2}{*}{ Tem TV } & & 0.002 & -0.038 & -0.005 \\
\hline & & $(0.006)$ & $(0.008)^{* * *}$ & $(0.011)$ \\
\hline \multirow[t]{2}{*}{ Tem Rádio } & & 0.039 & 0.007 & 0.041 \\
\hline & & $(0.005)^{* * *}$ & $(0.006)$ & $(0.011)^{* * *}$ \\
\hline \multirow[t]{2}{*}{ Assiste TV semanalmente } & & & 0.057 & 0.028 \\
\hline & & & $(0.010)^{* * *}$ & $(0.011)^{* *}$ \\
\hline \multirow[t]{2}{*}{ Ouve rádio semanalmente } & & & 0.042 & 0.005 \\
\hline & & & $(0.007)^{* * *}$ & $(0.010)$ \\
\hline \multirow[t]{2}{*}{ Trabalhador Agrícola } & & & & -0.032 \\
\hline & & & & $(0.010)^{* * *}$ \\
\hline Observações & 30,388 & 29,734 & 29,704 & 15,765 \\
\hline
\end{tabular}

Notas: Significância *** $p<0.01,{ }^{*} p<0.05,{ }^{*} p<0.1$. Todas as regressões acima utilizam somente a população analfabeta e utilizam erros-padrão robustos a autocorrelação serial no nível das UFs. As diferentes especificações são: (1) não inclui controles individuais; (2) inclui controles demográficos individuais; (3) inclui controles para o consumo de informação; (4) inclui controle que indica se o indivíduo é trabalhador agrícola e restringe amostra aos analfabetos ocupados. 
Tabela 4: Heterogeneidades por características dos eleitores analfabetos

\begin{tabular}{|c|c|c|c|}
\hline & \multicolumn{3}{|c|}{ Variável dependente: Tem título eleitoral (dummy) } \\
\hline & (1) & (2) & (3) \\
\hline \multirow[t]{2}{*}{ Arena * Rural } & 0.102 & 0.084 & -0.069 \\
\hline & $(0.040)^{* *}$ & $(0.050)$ & $(0.062)$ \\
\hline \multirow[t]{2}{*}{ Arena * Ln (RDPC) } & -0.038 & -0.021 & -0.070 \\
\hline & $(0.033)$ & $(0.038)$ & $(0.027)^{* *}$ \\
\hline \multirow[t]{2}{*}{ Arena * Assiste TV } & & -0.115 & -0.144 \\
\hline & & $(0.067)$ & (0.088) \\
\hline \multirow[t]{2}{*}{ Arena * Ouve rádio } & & -0.076 & -0.072 \\
\hline & & $(0.027)^{* *}$ & $(0.057)$ \\
\hline \multirow[t]{2}{*}{ Arena * Trabalhador Agrícola } & & & 0.214 \\
\hline & & & $(0.043)^{* * *}$ \\
\hline \multirow[t]{2}{*}{ Trabalhador Agrícola } & & & -0.166 \\
\hline & & & $(0.025)^{* * *}$ \\
\hline \multirow[t]{2}{*}{ Rural } & -0.057 & -0.047 & 0.060 \\
\hline & $(0.025)^{* *}$ & $(0.031)$ & (0.039) \\
\hline \multirow[t]{2}{*}{ Metropolitano } & -0.052 & -0.052 & -0.062 \\
\hline & $(0.033)$ & $(0.033)$ & $(0.017)^{* * *}$ \\
\hline \multirow[t]{2}{*}{ Homem } & 0.130 & 0.130 & 0.094 \\
\hline & $(0.016)^{* * *}$ & $(0.016)^{* * *}$ & $(0.012)^{* * *}$ \\
\hline \multirow[t]{2}{*}{ Idade } & 0.024 & 0.024 & 0.020 \\
\hline & $(0.001)^{* * *}$ & $(0.001)^{* * *}$ & $(0.001)^{* * *}$ \\
\hline \multirow[t]{2}{*}{ Idade2 } & -0.000 & -0.000 & -0.000 \\
\hline & $(0.000)^{* * *}$ & $(0.000)^{* * *}$ & $(0.000)^{* * *}$ \\
\hline \multirow[t]{2}{*}{ Branco } & -0.024 & -0.024 & 0.004 \\
\hline & $(0.011)^{* *}$ & $(0.011)^{* *}$ & (0.005) \\
\hline \multirow[t]{2}{*}{$\operatorname{Ln}(\mathrm{RDPC})$} & 0.016 & 0.005 & 0.035 \\
\hline & $(0.021)$ & $(0.025)$ & $(0.019)^{*}$ \\
\hline \multirow[t]{2}{*}{ Tem TV } & -0.035 & -0.037 & -0.008 \\
\hline & $(0.008)^{* * *}$ & $(0.007)^{* * *}$ & $(0.010)$ \\
\hline \multirow[t]{2}{*}{ Tem Rádio } & 0.004 & 0.005 & 0.039 \\
\hline & $(0.006)$ & $(0.006)$ & $(0.011)^{* * *}$ \\
\hline \multirow[t]{2}{*}{ Assiste TV semanalmente } & 0.059 & 0.130 & 0.121 \\
\hline & $(0.010)^{* * *}$ & $(0.044)^{* * *}$ & $(0.060)^{*}$ \\
\hline \multirow[t]{2}{*}{ Ouve rádio semanalmente } & 0.043 & 0.088 & 0.047 \\
\hline & $(0.006)^{* * *}$ & $(0.015)^{* * *}$ & $(0.036)$ \\
\hline EF dos estados & Sim & Sim & Sim \\
\hline Observações & 30,447 & 30,447 & 16,129 \\
\hline
\end{tabular}

Notas: Significância *** $p<0.01,{ }^{*} p<0.05,{ }^{*} p<0.1$. Todas as regressões acima utilizam somente a população analfabeta, utilizam erros-padrão robustos a autocorrelação serial no nível das UFs e incluem efeitos fixos para os estados. As diferentes especificações são:: (1) inclui controles individuais e interações entre a presença da ARENA e características demográficas; (2) inclui interações entre a presença da ARENA e o consumo de informação; (3) inclui controle que indica se o indivíduo é trabalhador agrícola (e sua interação com a presença da ARENA) e restringe amostra aos analfabetos ocupados. 
Tabela 5: Nível de conhecimento político e participação cívica dos eleitores analfabetos

\begin{tabular}{|c|c|c|c|c|c|c|}
\hline & \multicolumn{6}{|c|}{ Variáveis dependentes (dummies) } \\
\hline & $\begin{array}{l}\text { Sabe quem } \\
\text { é o prefeito }\end{array}$ & $\begin{array}{l}\text { Sabe quem é o } \\
\text { governador }\end{array}$ & $\begin{array}{l}\text { Sabe quem é } \\
\text { o presidente }\end{array}$ & $\begin{array}{l}\text { Filiado a } \\
\text { um partido }\end{array}$ & $\begin{array}{l}\text { Membro de } \\
\text { um sindi- } \\
\text { cato }\end{array}$ & $\begin{array}{c}\text { Não possui } \\
\text { critério para } \\
\text { votar }\end{array}$ \\
\hline & (1) & (2) & (3) & (4) & (5) & (6) \\
\hline \multirow[t]{2}{*}{ Arena * Rural } & 0.098 & 0.206 & 0.113 & 0.035 & 0.054 & -0.102 \\
\hline & (0.079) & $(0.164)$ & $(0.145)$ & $(0.022)$ & $(0.074)$ & $(0.038)^{* *}$ \\
\hline \multirow[t]{2}{*}{ Arena * Ln (RDPC) } & -0.197 & -0.099 & -0.101 & 0.022 & -0.081 & 0.012 \\
\hline & $(0.042)^{* * *}$ & $(0.063)$ & $(0.043)^{* *}$ & $(0.007)^{* *}$ & $(0.047)$ & $(0.035)$ \\
\hline \multirow[t]{2}{*}{ Arena * Assiste TV } & -0.259 & -0.177 & -0.162 & -0.003 & -0.034 & -0.039 \\
\hline & $(0.064)^{* * *}$ & $(0.078)^{* *}$ & $(0.063)^{* *}$ & $(0.017)$ & $(0.036)$ & (0.04w8) \\
\hline \multirow[t]{2}{*}{ Arena * Ouve rádio } & 0.015 & -0.103 & 0.059 & -0.017 & 0.029 & 0.152 \\
\hline & $(0.091)$ & $(0.085)$ & $(0.088)$ & $(0.016)$ & $(0.023)$ & $(0.034)^{* * *}$ \\
\hline \multirow[t]{2}{*}{$\begin{array}{c}\text { Arena * Trabalhador } \\
\text { Agrícola }\end{array}$} & 0.004 & 0.035 & 0.059 & -0.044 & 0.092 & 0.169 \\
\hline & $(0.103)$ & $(0.127)$ & $(0.116)$ & $(0.028)$ & $(0.115)$ & $(0.089)^{*}$ \\
\hline \multirow[t]{2}{*}{ Trabalhador Agrícola } & -0.029 & -0.056 & -0.107 & 0.020 & -0.007 & -0.082 \\
\hline & $(0.064)$ & $(0.086)$ & (0.073) & $(0.018)$ & (0.068) & $(0.055)$ \\
\hline \multirow[t]{2}{*}{ Rural } & -0.130 & -0.156 & -0.088 & -0.025 & -0.014 & 0.077 \\
\hline & $(0.047)^{* *}$ & $(0.104)$ & $(0.089)$ & $(0.015)$ & $(0.052)$ & $(0.024)^{* * *}$ \\
\hline \multirow[t]{2}{*}{ Metropolitano } & -0.208 & 0.009 & 0.053 & -0.014 & -0.006 & 0.039 \\
\hline & $(0.040)^{* * *}$ & $(0.026)$ & $(0.030)^{*}$ & $(0.004)^{* * *}$ & $(0.013)$ & $(0.009)^{* * *}$ \\
\hline \multirow[t]{2}{*}{ Homem } & 0.089 & 0.206 & 0.205 & 0.011 & 0.080 & -0.135 \\
\hline & $(0.012)^{* * *}$ & $(0.024)^{* * *}$ & $(0.025)^{* * *}$ & $(0.003)^{* * *}$ & $(0.009)^{* * *}$ & $(0.019)^{* * *}$ \\
\hline \multirow[t]{2}{*}{ Idade } & 0.008 & 0.009 & 0.006 & 0.001 & 0.008 & -0.006 \\
\hline & $(0.002)^{* * *}$ & $(0.002) * * *$ & $(0.002)^{* * *}$ & $(0.000)^{* * *}$ & $(0.001)^{* * *}$ & $(0.002)^{* *}$ \\
\hline \multirow[t]{2}{*}{ Idade2 } & -0.000 & -0.000 & -0.000 & -0.000 & -0.000 & 0.000 \\
\hline & $(0.000)^{* * *}$ & $(0.000)^{* * *}$ & $(0.000)^{* * *}$ & $(0.000)^{* * *}$ & $(0.000)^{* * *}$ & $(0.000)^{* * *}$ \\
\hline \multirow[t]{2}{*}{ Branco } & 0.010 & 0.026 & 0.026 & 0.001 & 0.003 & -0.026 \\
\hline & $(0.012)$ & $(0.013)^{*}$ & $(0.013)^{*}$ & $(0.002)$ & $(0.006)$ & $(0.011)^{* *}$ \\
\hline \multirow[t]{2}{*}{ Ln (RDPC) } & 0.116 & 0.083 & 0.102 & -0.011 & 0.044 & -0.023 \\
\hline & $(0.029) * * *$ & $(0.041)^{*}$ & $(0.027)^{* * *}$ & $(0.005)^{* *}$ & $(0.027)$ & $(0.020)$ \\
\hline \multirow[t]{2}{*}{ Tem TV } & 0.014 & 0.096 & 0.125 & 0.003 & -0.002 & -0.004 \\
\hline & $(0.018)$ & $(0.023)^{* * *}$ & $(0.017)^{* * *}$ & $(0.006)$ & $(0.017)$ & $(0.013)$ \\
\hline \multirow[t]{2}{*}{ Tem Rádio } & 0.052 & 0.062 & 0.065 & 0.005 & 0.001 & -0.024 \\
\hline & $(0.017)^{* * *}$ & $(0.020)^{* * *}$ & $(0.018)^{* * *}$ & $(0.003)$ & $(0.008)$ & $(0.014)^{*}$ \\
\hline \multirow[t]{2}{*}{$\begin{array}{c}\text { Assiste TV } \\
\text { semanalmente }\end{array}$} & 0.200 & 0.174 & 0.168 & 0.007 & 0.023 & -0.029 \\
\hline & $(0.040)^{* * *}$ & $(0.048)^{* * *}$ & $(0.037)^{* * *}$ & $(0.012)$ & $(0.025)$ & $(0.032)$ \\
\hline \multirow[t]{2}{*}{$\begin{array}{c}\text { Ouve rádio } \\
\text { semanalmente }\end{array}$} & 0.008 & 0.121 & 0.000 & 0.012 & 0.020 & -0.127 \\
\hline & $(0.065)$ & $(0.055)^{* *}$ & $(0.050)$ & $(0.007)^{*}$ & $(0.015)$ & $(0.022)^{* * *}$ \\
\hline EF dos estados & Sim & Sim & Sim & Sim & Sim & Sim \\
\hline Observações & 9,468 & 9,467 & 9,465 & 16,108 & 16,108 & 9,465 \\
\hline
\end{tabular}

Notas: Significância *** $p<0.01,{ }^{*} p<0.05,{ }^{*} p<0.1$. Todas as regressões acima utilizam somente a população analfabeta, utilizam erros-padrão robustos a autocorrelação serial no nível das UFs e incluem efeitos fixos para os estados. 


\section{REFERÊNCIAS BIBLIOGRÁFICAS}

Acemoglu, D. and J. Robinson (2006). De facto political power and institutional persistence. American Economic Review 96 (2), 325-330.

Acemoglu, D. and J. Robinson (2008). Persistence of power, elites and institutions. The American Economic Review 98, 267-293.

Aghion, P., A. Alesina, and F. Trebbi (2004). Endogenous political institutions. The Quarterly Journal of Economics 39, 565-611.

Baland, J. and J. Robinson (2008). Land and power: Theory and evidence from chile. The American Economic Review 98, 1737-1765.

Bellows, J. and E. Miguel (2009). War and local collective action in sierra leone. Journal of Public Economics 93 (11-12), 1144-1157.

Blattman, C. (2009). From violence to voting: War and political participation in uganda. American Political Science Review 103 (2), 231-247.

Cammack, P. (1982). Clientelism and military government in brazil. In C. Clapham (Ed.), Private Patronage and Public Power: Political Clientelism in the Modern State, pp. 53-75. New York: St. Martin's.

Dee, T. S. (2004). Are there civic returns to education? Journal of Public Economics 88, 1697-1720.

Glaeser, E. L., G. A. M. Ponzetto, and A. Shleifer (2007). Why does democracy need education? Journal of Economic Growth 12, 77-99.

Hagopian, F. (1975). The Politics of Oligarchy: The Persistence of Traditional Elites in Contemporary Brazil. Ph.D. thesis, Massachusetts Institute of Technology, Cambridge, MA.

Hagopian, F. (1996). Traditional Politics and Regime Change in Brazil. New York: Cambridge University Press.

Houtzager, P. P. and M. J. Kurtz (2000). The institutional roots of popular mobilization: State transformation and rural politics in brazil and chile, 1960-1995. Comparative Studies in Society and History 42, 394-424.

Kinzo, M. D. G. (1988). Legal Oposition Politics Under Authoritarian Rule in Brazil. New York: St. Martin's.

Larcinese, V. (2007). Does political knowledge increase turnout? evidence from the 1997 british general election. Public Choice 131, 387-411.

Leal, V. N. (1949). Coronelismo, Enxada e Voto (1975 ed.). São Paulo: Editora Alfa-Ômega.

Limongi, F. (2012). Eleições e democracia no Brasil: Victor Nunes Leal e a transição de 1945. Dados $55,37-69$.

Milligan, K., E. Moretti, and P. Oreopoulos (2004). Does education improve citizenship? evidence from the united states and the united kingdom. Journal of Public Economics 88, 1667-1695.

Power, T. J. (2000). The Political Right in Postauthoritarian Brazil: Elites, Institutions and Democratization. University Park, Pennsylvania: The Pennsylvania State University Press.

Verba, S. and N. H. Nie (1972). Introduction to Economic Growth (2001 ed.). New York: W. W. Norton \& Company.

Verba, S., K. L. Schlozman, and H. E. Brady (2000). Rational action and political activity. Journal of Theoretical Politics 12 (3), 243-268.

Wolfinger, R. E. and S. J. Rosenstone (1980). Who Votes? New Haven, CT: Yale University Press. 